\title{
Veinte años del Régimen Andino De Acceso a Recursos Genéticos
}

\author{
Mónica Ribadeneira Sarmiento*
}

\section{Resumen}

El artículo buscar contribuir al conocimiento del régimen legal andino de acceso a recursos genéticos, cuyo instrumento central es la Decisión Andina 391, promulgada en 1996. Se analiza la norma y se presentan sus más evidentes virtudes y limitaciones. Se incluye información sobre la evolución nacional de la decisión en cada uno de los países andinos. El artículo contiene un apartado referido al futuro de la norma en el actual escenario de reingeniería del Sistema Andino de Integración (SAI).

Se han consultado documentos, fuentes oficiales, artículos de expertos y entrevistas. El artículo se estructura de la siguiente manera: los orígenes de la norma; el análisis y contenido de la norma andina; el proceso de reglamentación en los países andinos; las virtudes y limitaciones; la coyuntura y el futuro, y, por último, las conclusiones.
Palabras clave: leyes sobre medio ambiente, salud y seguridad, derecho internacional, América Latina; Caribe, gestión de la innovación tecnológica y de la investigación y desarrollo $(\mathrm{I}+\mathrm{D})$, economía ecológica, servicios del ecosistema, conservación de la biodiversidad, bioeconomía.

\section{YEARS OF THE ANDEAN REGIME ON ACCESS TO GENETIC RESOURCES}

\section{Abstract}

Article seeks to contribute to the knowledge of the Andean legal regime on access to genetic resources. The main instrument was the Andean Decision 391 which was enacted in 1996. It is analyzed the legal text and the most obvious virtues and limitations that have since been able to appreciate are presented. One chapter contains information

\footnotetext{
* Doctora en Jurisprudencia. Investigadora independiente (Ecuador). mribadeneira@gmail.com Recibido: 14/09/2016/ Modificado: 16/11/2016/ Aceptado: 20/11/2016.

Para citar este artículo

Ribadeneira Sarmiento, M. (2017). Veinte años del Régimen Andino de Recursos Genéticos. opera, 20, pp. $179-204$. DoI: https://doi.org/10.18601/16578651.n20.09
} 
about the national developments of the decision in each of the Andean countries. The article contains a section referring to the future of the norm in the current scenario of reengineering the Andean Integration System (SAI).

For the preparation of the article have been consulted documents, official sources and expert articles and interviews. It is structured as follows: origins of the standard; analysis of the Andean legal text; regulatory process in all the Andean countries; strengths and limitations; situation and future, and conclusions.

Key words: Environmental, health and security laws, international law, Latin America; Caribbean, management of technological innovation and research and development (R\&D), Ecological Economy: ecosystem services, biodiversity conservation, bio economy.

\section{INTRODUCCIÓN}

La diversidad biológica es el capital natural de los países, y aunque generalmente su valor no sea reconocido como estratégico, su conservación y uso sustentable son imperativos básicos para el bienestar de la sociedad. La diversidad biológica se manifiesta en tres niveles: 1) ecosistemas, 2) especies y 3) genes. En este último nivel están los recursos genéticos, que son el material que contiene información genética de un ser vivo (vegetal, animal, hongo o microorganismo), dicho material tiene o puede tener valor o uso real o potencial.

La información genética son las unidades funcionales de herencia, objeto de investigación en biología molecular, bioquímica y bioinformática. Las posibilidades y aplica- ciones prácticas de los hallazgos basados en información genética son altamente relevantes para las industrias de alimentos, farmacológica, cosmética, entre otras. No existe certeza sobre las potencialidades que los productos sintetizados a partir de principios activos y recursos genéticos puedan tener.

Por estas y otras razones es tan importante contar con un marco legal para acceder y usar los recursos genéticos. Cuando en 1996 se promulgó en la región andina la Decisión 391, que establece el Régimen Común sobre Acceso a los Recursos Genéticos (en adelante Decisión 391), no existía otro precedente mundial que el Convenio de la Diversidad Biológica (1992), y eran muchas las expectativas ante la falta de claridad legal y científica sobre los recursos genéticos y su potencial. La expedición de la mencionada decisión fue un hito global sin precedentes en la materia; este artículo aspira a difundir su contenido y entender sus implicaciones.

\section{LOS ORÍGENES DE LA DECISIÓN 391}

El Convenio de la Diversidad Biológica (en adelante $\mathrm{CDB}$ ) fue adoptado en Nairobi en 1992 y entró en vigor el 29 de diciembre de 1993 (Glowka, 1996).

Los objetivos del CDB son: 1) la conservación de la diversidad biológica, 2) el uso sustentable de sus componentes, y 3) la distribución justa y equitativa de beneficios del acceso a los recursos genéticos (art. $1 \mathrm{CDB}$ ); todos ellos estrechamente interrelacionados entre sí. Con su tercer objetivo, el CDB establece los lineamientos del acceso a los recursos genéticos, 
que posteriormente serían desarrollados por el Protocolo de Nagoya sobre el Acceso a los Recursos Genéticos y Participación Justa y Equitativa en los Beneficios que se Deriven de su Utilización (en adelante Protocolo de Nagoya).

El Protocolo de Nagoya es el instrumento legal más joven en el sistema de las Naciones Unidas aplicable a la conservación de la biodiversidad. Este instrumento es el marco jurídico internacional que desarrolla el tercer objetivo del CDB (1992), que es la participación justa y equitativa en los beneficios que se deriven de la utilización de los recursos genéticos. El Protocolo de Nagoya entró en vigor el 12 de octubre de 2014; lamentablemente, la extensión del presente artículo no permite profundizar en su análisis ni en las relaciones entre este y la Decisión Andina 391.

Acerca del CDB, es preciso seńala que este modificó el régimen legal de la diversidad biológica de res nullius a recurso soberano de los países. El concepto de res nullius o cosa de nadie es aquel bien que no pertenece a nadie y cuya primera concepción pertenece al derecho romano ${ }^{1}$ (Carrión, 1987).

El CDB define a los recursos genéticos $(\text { art. } 2 \mathrm{CDB})^{2}$ y establece principios para su acceso y la distribución de los beneficios que genere su utilización (arts. 15, 16 y 19 CDB). Se volverá al tema del ámbito al analizar la Decisión Andina 391.

Otros artículos del CDB abordan aspectos como la distribución de beneficios directamente vinculados al acceso a dichos recursos, y los siguientes:

1. El reconocimiento del aporte realizado por los pueblos indígenas y las comunidades locales a la conservación de la biodiversidad a través de sus conocimientos, innovaciones y prácticas tradicionales (art. 8j CDB).

2. La transferencia de tecnología (art. 16 $\mathrm{CDB})$.

3. El intercambio de información (art. 17 $\mathrm{CDB}$ )

4. La cooperación científica y técnica (art. 18).

5. La gestión de la biotecnología y la distribución de sus beneficios (art. 19 CDB).

6. Los recursos y mecanismos financieros (arts. 20 y $21 \mathrm{CDB})$.

En esencia, los temas claves en el $\mathrm{CDB}$ en materia de recursos genéticos son: 1) soberanía de los Estados sobre sus recursos genéticos, 2)

\footnotetext{
Carrión dice al respecto: "a lo largo de su historia Roma conoció diversas formas de propiedad: colectiva, familiar e individual”, y cita a Kaden quien dice: "los juristas romanos jamás tuvieron la idea de que el propietario fuera, en principio, amo absoluto y soberano de una cosa y de que su poder solo estuviera limitado excepcionalmente. Las reglas de derecho, la moral y la religión restringían su poder. En Roma todo propietario estaba obligado a ejercer sus derechos legalmente (malitis non sit indulgendum), a respetar los intereses de su familia, a considerar los intereses de sus vecinos y a tener en cuenta, sobre todo el interés público (salus publica suprema lex)” (Carrión, 1987).

2 Convenio de Diversidad Biológica. Artículo 2: Términos utilizados. A los efectos de este convenio: Por “recursos genéticos" se entienden los recursos genéticos, los organismos o partes de ellos, las poblaciones, o cualquier otro tipo del componente biótico de los ecosistemas de valor o utilidad real o potencial para la humanidad.
} 
facilitación del acceso a los recursos genéticos, 3) derechos del país de origen de los recursos genéticos, 4) consentimiento fundamentado previo, 5) condiciones mutuamente acordadas, 6) distribución justa y equitativa de los beneficios, y 7) derechos de los pueblos indígenas y las comunidades locales (Ribadeneira Sarmiento, 2016).

La mencionada modificación de estatus de res nullius a recurso soberano que nació con el CDB inició el desafío de su aplicación a nivel mundial. La primera vez que este desafío fue asumido fue en la región andina por la entonces Junta del Acuerdo de Cartagena, actual Comunidad Andina de Naciones (en adelante CAN $)^{3}$, que aprobó la Decisión Andina 391 (Estrella, Manosalvas, Mariaca y Ribadeneira Sarmiento, 2005).

La CAN es el organismo subregional de integración con personería jurídica internacional, actualmente integrada por Bolivia, Colombia, Ecuador y Perú , y por los órganos e instituciones del Sistema Andino de Integración (en adelante SAI).

El sai es el conjunto de órganos e instituciones cuyas acciones están encaminadas a lograr los siguientes objetivos comunes: 1) profundizar la integración subregional andina, 2) promover su proyección externa y 3) robustecer las acciones relacionadas con estos procesos. El objetivo general de la CAN es promover el desarrollo equilibrado y armónico de los países miembros en condiciones de equidad, mediante la integración y la cooperación económica y social (Comunidad Andina de Naciones, s. f.).

$\mathrm{Al}$ año siguiente a la vigencia del $\mathrm{CDB}$, se aprobó la Decisión Andina 345 sobre el Régimen Común de Protección a los Derechos de los Obtentores de Variedades Vegetales (en adelante Decisión 345) que es el antecedente más inmediato de la Decisión Andina 391 (Estrella et al., 2005).

El establecimiento del régimen para la protección a los obtentores de variedades vegetales tenía el triple objetivo de: 1) reconocer los derechos de los obtentores de nuevas variedades vegetales, 2) fomentar la investigación y 3) propiciar las actividades de transferencia de tecnología 5 . La Decisión 345 se aplica a todos los géneros y especies botánicas cuyo cultivo, posesión o utilización no sean prohibidos ${ }^{6}$.

3 La Junta del Acuerdo de Cartagena nació en 1969 y ha sido conocida también como Pacto Andino o Grupo Andino y, actualmente, Comunidad Andina (CAN).

4 Los miembros fundadores en 1969 fueron Bolivia, Colombia, Chile, Ecuador y Perú; Venezuela se incorporó formalmente en 1973: Chile se retiró en 1976. En 2006, Chile se incorporó con calidad de Miembro Asociado, aunque ello no ha supuesto necesariamente su reingreso activo al grupo, sino más bien un carácter de observador. Venezuela se retiró en el mismo año.

5 Decisión Andina 345. Capítulo I: Del objeto y ámbito de aplicación. Artículo 1. La presente Decisión tiene por objeto:

a) Reconocer y garantizar la protección de los derechos del obtentor de nuevas variedades vegetales mediante el otorgamiento de un Certificado de Obtentor;

b) Fomentar las actividades de investigación en el área andina;

c) Fomentar las actividades de transferencia de tecnología al interior de la Subregión y fuera de ella. 
La Decisión 345 contiene una disposición transitoria, concretamente la tercera, con un mandato claro: "se aprobará un régimen común sobre acceso a los recursos biogenéticos y garantía a la bioseguridad de la Subregión"7, dicho régimen es lo que conocemos como Decisión 391, que se analizará a continuación. La Decisión 345 es la primera disposición andina que hizo referencia directa a aspectos ambientales, y en particular al CDB, creando así una nueva etapa en los procesos andinos de integración, esta vez en el ámbito del ambiente (Estrella et al., 2005).

\section{LA DECISIÓN 391: ANÁLISIS Y CONTENIDO}

\section{Carácter de la norma andina}

Previo al análisis de la Decisión Andina 391 es pertinente señalar que una importante particularidad del ordenamiento jurídico andino es su carácter supranacional, es decir que se debe aplicar en forma inmediata y directa, con supremacía sobre el derecho nacional de los países miembros.

La supranacionalidad se caracteriza por la aplicación directa y su preeminencia. La aplicación directa implica que para que las normas comunitarias surtan efecto no se requiere de procedimientos de recepción o ratificación en el ordenamiento interno de los países miembros. En tal sentido, estas normas andinas son de cumplimiento obligatorio e inmediato por estos países en todas sus instancias, por los órganos de la CAN y los particulares. Así, la normativa andina obliga a todos los poderes de los Estados, sin distinción en todo su territorio y sin limitaciones de orden regional, departamental, provincial o municipal. Por tanto, el ciudadano común adquiere obligaciones y derechos cuyo cumplimiento se puede exigir tanto ante sus tribunales nacionales como ante las instancias administrativa y judicial comunitarias (Rosell, 1999).

La preeminencia de las normas andinas ha sido destacada reiteradamente por el Tribunal de Justicia de la CAN como la segunda característica del derecho comunitario andino, señalando que prevalece en su aplicación sobre las normas internas o nacionales, cualquiera sea el rango de esta última. De esta manera, de presentarse un conflicto entre las normas nacionales de los países miembros y las normas comunitarias, estas últimas se aplican con preferencia a las primeras (Rosell, 1999).

Este principio de primacía de las normas comunitarias permite que los países miembros no puedan alegar normas de su derecho interno para dejar de cumplir las obligaciones

6 Decisión Andina 345. Capítulo I: Del objeto y ámbito de aplicación. Artículo 2. El ámbito de aplicación de la presente Decisión se extiende a todos los géneros y especies botánicas siempre que su cultivo, posesión o utilización no se encuentren prohibidos por razones de salud humana, animal o vegetal.

Decisión Andina 345. Disposiciones transitorias. Tercera: Los países miembros aprobarán, antes del 31 de diciembre de 1994, un Régimen Común sobre acceso a los recursos biogenéticos y garantía a la bioseguridad de la Subregión, de conformidad con lo dispuesto en el Convenio sobre la Diversidad Biológica adoptado en Río de Janeiro el 05 de junio de 1992. 
adquiridas en el marco del proceso de integración (Rosell, 1999).

\section{Elementos claves de la Decisión Andina 391}

Es importante anotar que el primer elemento clave de la norma andina es que implícitamente reconoce que la diversidad biológica está distribuida independientemente de las fronteras de los Estados, y que existen recursos transfronterizos que comparten dos o más Estados, o que se trata de especies que migran entre ellos.

Las principales características de esta norma andina son:

1. La determinación de nuevo régimen legal aplicable a los recursos genéticos basado en la propiedad del Estado sobre los mismos, de conformidad con su condición de "bien público administrado por el Estado".

2. La exclusión de los recursos genéticos del régimen de:

- Propiedad de los recursos biológicos que contienen a los primeros. Como es conocido, los recursos biológicos son susceptibles de la propiedad privada, no así los genéticos que son recurso estatal.

- Propiedad e incluso posesión del lugar donde se encuentren los recursos genéticos.
- Propiedad de los conocimientos asociados a los recursos genéticos (también conocido como componente intangible), cuyos titulares son las comunidades indígenas, afrodescendientes y locales.

3. La necesidad de autorizar el uso de los recursos genéticos por terceros a través de un contrato celebrado entre el tercero interesado y la Autoridad Ambiental Nacional, y, en tal sentido, la obligación de cumplir con el procedimiento, los requisitos y las condiciones exigidas.

4. La imposibilidad de que el recurso genético como tal pase a ser parte de propiedad privada alguna, salvo que luego de celebrado el contrato de acceso se hubiera desarrollado un nuevo producto susceptible de protección mediante algún sistema de propiedad intelectual. Este producto protegido no recibirá el mismo tratamiento legal que aquel que recibió el recurso genético que se solicitó inicialmente.

Entre los aspectos relevantes de la Decisión 391 deben señalarse:

1. Ámbito de aplicación. Los recursos genéticos de origen de los países miembros que incluyen $(\operatorname{art.~3})^{8}$ :

8 Decisión Andina 391. Título III: Del ámbito. Artículo 3. La presente Decisión es aplicable a los recursos genéticos de los cuales los Países Miembros son países de origen, a sus productos derivados, a sus componentes intangibles y a los recursos genéticos de las especies migratorias que por causas naturales se encuentren en el territorio de los Países Miembros. 
- Aquellos de especies migratorias que por causas naturales se encuentren dentro su jurisdicción.

- Los productos derivados.

- Los componentes intangibles de dichos recursos genéticos.

Del ámbito de aplicación de la Decisión 391 se exceptúan los siguientes recursos genéticos (art. 4)

- Los que existen en los países andinos en condiciones ex situ, es decir que provienen de otros países. Este es el caso de las especies que se mantienen en zoológicos y herbarios de los países andinos como muestras de la diversidad biológica de otros países.

- Aquellos protegidos por sistemas de propiedad intelectual vigentes en los países miembros ${ }^{10}$.
- Los humanos, de la misma forma que el CDB.

- Los utilizados por las comunidades indígenas, afrodescendientes y locales de los países miembros bajo prácticas consuetudinarias.

- Aquellos recursos fitogenéticos que constan en el Anexo al Tratado Internacional de Recursos Fitogenéticos de la Organización de las Naciones Unidas para la Alimentación y la Agricultura (FAO, por sus siglas en inglés) ${ }^{11}$, porque estos están sometidos al régimen del tratado por voluntad de los países que lo suscribieron.

2. Estatus del recurso genético. La Decisión 391 es más específica que $\mathrm{CDB}^{12}$, no solo porque agrega "los Países Miembros ejercen soberanía sobre sus recursos genéticos $y$ en consecuencia determinan las con-

9 Decisión Andina 391. Artículo 4. Se excluyen del ámbito de esta Decisión:

a) Los recursos genéticos humanos y sus productos derivados; $y$,

b) El intercambio de recursos genéticos, sus productos derivados, los recursos biológicos que los contienen, o de los componentes intangibles asociados a éstos, que realicen las comunidades indígenas, afroamericanas y locales de los Países Miembros entre sí y para su propio consumo, basadas en sus prácticas consuetudinarias.

10 Este es el caso de los microorganismos y las variedades vegetales protegidos en los países andinos mediante las Decisiones Andinas decisiones 344 y 345, sobre Régimen Común de Propiedad Industrial y sobre Régimen Común de Protección a Obtentores de Variedades Vegetales, respectivamente.

11 El Tratado Internacional sobre Recursos Fitogenéticos de la FAO (conocido también como Tratado de la FAO) entró en vigor el 29 de junio de 2004 y propone un sistema facilitado de acceso para los cultivos de importancia agronómica relevantes para la seguridad alimentaria. Se establece como mecanismo los acuerdos de transferencia de material (ATM) que se aplica solamente a los cultivos enlistados en el Anexo 2 del Tratado; ambas diferencias: 1) el sistema facilitado, y 2) los acuerdos de transferencia, constituyen dos diferencias básicas con la Decisión Andina 391. Para profundizar en el tema del Tratado de la FaO se remite a Tapia, Falconí, Martínez, Buitrón y Ribadeneira Sarmiento (2012).

12 El CDB reconoce que los países de origen son los autorizados para disponer de sus recursos genéticos en reconocimiento a la soberanía de los Estados sobre su diversidad biológica (art. 15). 
diciones para su acceso" 13 , sino porque los califica, y a sus productos derivados, como "bienes o patrimonio de la Nación o del Estado".

La norma andina agrega que "dichos recursos son inalienables, imprescriptibles e inembargables" ${ }^{14}$. Esto es especialmente relevante en materia de los productos derivados y los beneficios que genera su comercialización.

3. Mecanismo de acceso. El mecanismo de acceso a los recursos genéticos es el contrato de acceso a dichos recursos.

Además de las normas de la Decisión 391 para la elaboración del contrato deben considerarse las resoluciones 414 y 415 de la Junta del Acuerdo de Cartagena: Adopción del modelo referencial de contrato de acceso a recursos genéticos ${ }^{15}$, ambas promulgadas en 1996. A continuación se profundizará en este mecanismo de acceso.

\section{Procedimiento de acceso}

Como se mencionó, el mecanismo determinado por la Decisión 391 es el contrato de acceso a los recursos genéticos (arts. 16 y ss., Título v: Del Procedimiento de Acceso).

Las disposiciones de la Decisión 391 en relación con el procedimiento de acceso a recursos genéticos son claras respecto de la secuencia y duración entre fases. En la figura 1 se presenta un esquema del procedimiento aplicable.

\section{PROCESO DE REGLAMENTACIÓN NACIONAL DE LA DECISIÓN ANDINA 391}

Como es bien sabido, una de las características de las normas andinas es que son de aplicación directa; esta capacidad nace en el Tratado de Creación del Tribunal de Justicia de la CAN vigente ${ }^{16}$ y en el Protocolo de

13 Decisión 391. Título Iv: De los principios. Capítulo I: De la soberanía sobre los recursos genéticos y sus productos derivados. Artículo 5. Los Países Miembros ejercen soberanía sobre sus recursos genéticos y sus productos derivados y en consecuencia determinan las condiciones de su acceso, de conformidad con lo dispuesto en la presente Decisión. La conservación y utilización sostenible de los recursos genéticos y sus productos derivados, serán reguladas por cada País Miembro, de acuerdo con los principios y disposiciones contenidos en el Convenio de la Diversidad Biológica y en la presente Decisión.

14 Decisión 391. Artículo 6. Los recursos genéticos y sus productos derivados, de los cuales los Países Miembros son países de origen, son bienes o patrimonio de la Nación o del Estado de cada País Miembro, de conformidad con lo establecido en sus respectivas legislaciones internas. Dichos recursos son inalienables, imprescriptibles e inembargables, sin perjuicio de los regímenes de propiedad aplicables sobre los recursos biológicos que los contienen, el predio en que se encuentran, o el componente intangible asociado.

15 El Modelo Referencial del contrato contiene los principales aspectos del desarrollo de un proyecto de acceso a recursos genéticos y, en tal sentido, constituye también un referente de este tipo de proyectos.

16 Tratado de Creación del Tribunal de Justicia de la Comunidad Andina.

Artículo 2. Las Decisiones obligan a los Países Miembros desde la fecha en que sean aprobadas por el Consejo Andino de Ministros de Relaciones Exteriores o por la Comisión de la Comunidad Andina. 
FIGURA 1. PROCEDIMIENTO DE ACCESO A RECURSOS GENÉTICOS

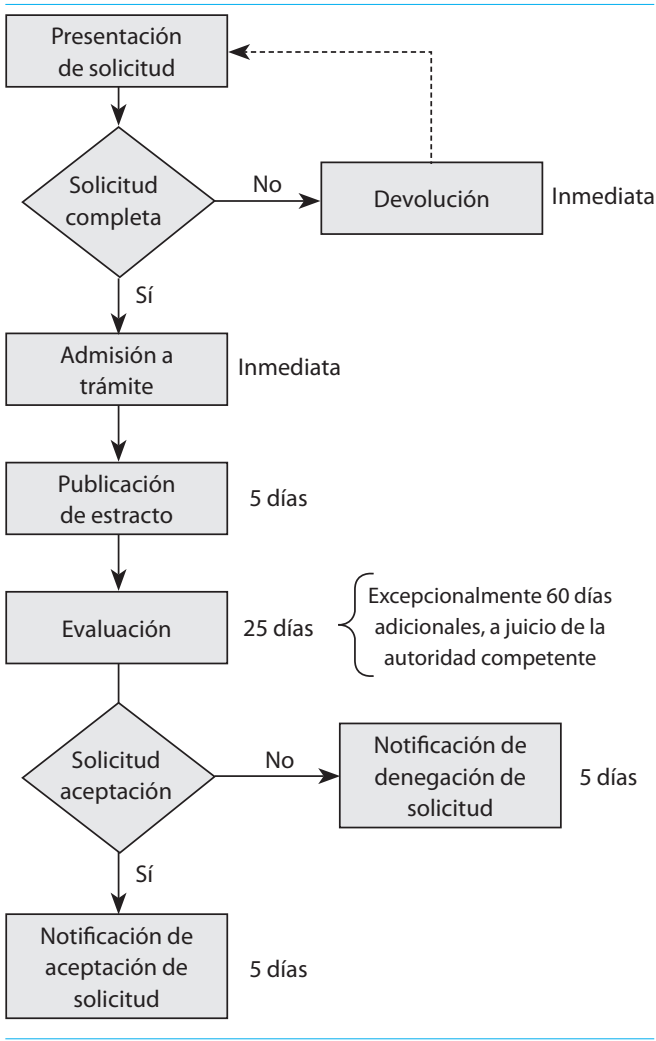

Fuente: Estrella (2005).

Cochabamba (modificatorio del anterior) que fue suscrito en $1996^{17}$; en este, se establece claramente que las decisiones serán directamente aplicables ${ }^{18}$.

Lo anterior implica que las normas comunitarias no requieren de procedimientos de recepción o ratificación en el ordenamiento interno de los países miembros, y que obligan directamente a todos los poderes de los Estados andinos, sin distinción y sin limitaciones de orden regional, departamental, provincial o municipal (Estrella et al.).

Una segunda característica es la preeminencia sobre las normas internas o nacionales, cualquiera sea el rango de esta última. De esta manera, de presentarse un conflicto entre las normas nacionales de los países miembros y las normas comunitarias, estas últimas se aplican con preferencia a las primeras. Este principio de primacía de las normas comunitarias permite que los países miembros no puedan alegar normas de su derecho interno para dejar de cumplir las obligaciones adquiridas en el marco del proceso de integración (Rosell, 1999).

Pese a estas dos características de la norma andina, algunos países miembros decidieron reglamentar la Decisión 391; a continuación se presenta un sumario de estos procesos nacionales.

17 Protocolo de Cochabamba. Artículo 2. Las Decisiones obligan a los Países Miembros desde la fecha en que sean aprobadas por el Consejo Andino de Ministros de Relaciones Exteriores o por la Comisión de la Comunidad Andina.

18 Protocolo de Cochabamba. Artículo 3. Las Decisiones del Consejo Andino de Ministros de Relaciones Exteriores o de la Comisión y las Resoluciones de la Secretaría General serán directamente aplicables en los Países Miembros a partir de la fecha de su publicación en la Gaceta Oficial del Acuerdo, a menos que las mismas señalen una fecha posterior.

Cuando su texto así lo disponga, las Decisiones requerirán de incorporación al derecho interno, mediante acto expreso en el cual se indicará la fecha de su entrada en vigor en cada País Miembro. 


\section{Bolivia}

La aplicación de la Decisión Andina 391 fue relativamente rápida en Bolivia, país que aprobó su reglamento en $1997^{19}$.

Bolivia no solo fue el primer país que reglamentó la Decisión Andina 391, sino que fue el primero en negociar y firmar un contrato de acceso a recursos genéticos. Este contrato se firmó en marzo de 2004 con la compañía suiza Migros para el acceso a recursos genéticos de cinco variedades de papa nativa (Ministerio de Desarrollo Sostenible, Viceministerio de Recursos Naturales y Medio Ambiente y Dirección General de Biodiversidad, 2004).

En algún momento se reportaron nueve solicitudes presentadas a la autoridad nacional, de las cuales solo una había concluido en contrato, precisamente el caso mencionado (Ministerio de Desarrollo Sostenible, Viceministerio de Recursos Naturales y Medio Ambiente, Dirección General de Biodiversidad, 2004). Al momento no existen informes oficiales que den cuenta de más avances en el tema.

Bolivia presentó su adscripción al Protocolo de Nagoya en octubre de 2016 y es parte de este desde enero de 2017 (Secretaría del Convenio de Diversidad biológica, s. f.).

\section{Colombia}

Colombia no cuenta con reglamento nacional de la Decisión Andina 391 y tampoco se encuentran disponibles análisis de evaluaciones oficiales sobre la eficacia de la norma.

A falta de reglamento nacional existen otros instrumentos nacionales que tienen por finalidad clarificar las reglas de acceso a recursos genéticos; se pueden citar como ejemplos:

- El Decreto 730 del Ministerio de Comercio Exterior de 1997, por el cual se determina la autoridad nacional competente en materia de acceso a los recursos genéticos.

- La Resolución 620 del Ministerio del Medio Ambiente de 1997, por la cual se delegan algunas funciones contenidas en la Decisión 391 de la Comisión del Acuerdo de Cartagena y se establece el procedimiento interno para tramitar las solicitudes de acceso a los recursos genéticos y sus productos derivados.

- La Resolución 1348 del Ministerio del Ambiente y Desarrollo Sostenible de 2014, por la cual se establecen las actividades que configuran acceso a los recursos genéticos y sus productos derivados para la aplicación de la Decisión Andina 391 de 1996 en Colombia y se toman otras determinaciones.

Lamentablemente, no existe información oficial sobre el proceso desarrollado entre 2011 y 2012, cuya finalidad era establecer sinergias que permitieran la suscripción del Protocolo de Nagoya y clarificaran requisitos

19 Bolivia. Reglamento de la Decisión 391, Régimen de Acceso a los Recursos Genéticos, promulgado el 21 de junio de 1997. Recuperado de http://www.lexivox.org/norms/BO-RE-Ds24676A.xhtml. 
para los diferentes contratos; este proceso no prosperó por la necesidad de efectuar una consulta previa.

\section{Ecuador}

Tras varios ańos de proceso, Ecuador promulgó su Reglamento Nacional al Régimen Común sobre Acceso a los Recursos Genéticos en aplicación a la Decisión 391 de la Comunidad Andina en $2011^{20}$, y para complementarlo, en 2015 publicó la norma que regula el procedimiento para la suscripción de Contratos Marco de Acceso a Recursos Genéticos ${ }^{21}$.

Varias han sido las iniciativas que se han promovido en Ecuador, sin embargo, los recursos genéticos como tema nunca han merecido atención prioritaria por parte de las autoridades nacionales y, por ello, no se han podido cristalizar ${ }^{22}$.

\section{Perú}

Perú cuenta con un reglamento nacional expedido por el Ministerio del Ambiente (en adelante MINAM) en $2009^{23}$, y al momento se prepara una reforma para compatibilizar el reglamento nacional con los principios y el texto del Protocolo de Nagoya ${ }^{24}$.

Aunque en Perú se necesitó más de una década para reglamentar la Decisión Andina 391, es destacable que durante este mismo tiempo existieron procesos muy importantes dedicados, por ejemplo, a la prevención de la biopiratería y la protección de los conocimientos tradicionales asociados a los recursos genéticos.

En materia de prevención a los accesos ilegítimos y casos de biopiratería se promulgó la Ley de Protección al Acceso a la Diversidad Biológica Peruana y los Conocimientos Colectivos de los Pueblos Indígenas ${ }^{25}$, que creó la Comisión Nacional de Lucha contra la Biopiratería que es la autoridad peruana responsable por "identificar y efectuar el seguimiento de las solicitudes de patentes de invención presentadas o patentes de invención concedidas en el extranjero, relacionadas con recursos biológicos o con conocimientos $\mathrm{CO}-$ lectivos de los pueblos indígenas del Perú”26.

20 Ecuador. Reglamento Nacional al Régimen Común Sobre Acceso a los Recursos Genéticos en Aplicación a la Decisión 391 de la Comunidad Andina, promulgado por vía del Decreto Ejecutivo 905, publicado en el Registro Oficial 553, 11 de octubre de 2011.

21 Ecuador. Norma que regula el procedimiento para la suscripción de Contratos Marco de Acceso a Recursos Genéticos, promulgado por el Acuerdo Ministerial 034, publicado en el Registro Oficial 449, 2 marzo del 2015.

22 Entrevista W. Rojas, ex-Punto Focal de Acceso a Recursos Genéticos del Ecuador, 30 de agosto de 2016.

23 Perú. Decreto Supremo 003-2009-Minam.

24 Entrevista M. Ruiz, 4 de abril de 2016.

25 Perú. Ley 28216. Ley de Protección al Acceso a la Diversidad Biológica Peruana y los Conocimientos Colectivos de los Pueblos Indígenas. Recuperado de http://www.wipo.int/wipolex/en/text.jsp?file_id=179602

26 Perú. Ley 28216. Ley de Protección al Acceso a la Diversidad Biológica Peruana y los Conocimientos Colectivos de los Pueblos Indígenas (art. 4 lit. c). 
De su lado, para atender la protección de los conocimientos tradicionales, en Perú existen varios instrumentos legales como la ley que establece el Régimen de Protección de los Conocimientos Colectivos de los Pueblos Indígenas vinculados a los Recursos Biológicos ${ }^{27}$.

\section{Venezuela}

Venezuela inició su separación de la CAN en 2006 por su inconformidad con los procesos de negociación de los Tratado de Libre Comercio (TlC) de Perú y Colombia con Estados Unidos; la separación finalizó en abril de 2011. La revisión legal de los mecanismos de acceso a recursos genéticos que aplica Venezuela con posterioridad a su salida de la CAN es un tema aún pendiente.

Mientras Venezuela fue miembro de la CAN se aplicó la decisión directamente; sin embargo, no existen informes nacionales que den cuenta de la aplicación de la norma andina.

$\mathrm{Al}$ momento, debido a la crisis que afronta este país, ya que no existe información disponible, no es posible estimar el interés por acceder a recursos genéticos ni tampoco analizar las acciones estatales adoptadas en la materia.

\section{VIRTUDES Y DEBILIDADES DE LA DECISIÓN ANDINA 391}

Encarar las virtudes y debilidades de la norma andina supone efectuar un análisis ob- jetivo y crítico de la Decisión 391, en el que es necesario distinguir de un lado la eficacia de la norma andina como precepto legal o fórmula legal, de la eficacia de su aplicación.

El primer aspecto atañe a la norma como formulación legal, mientras que el segundo tiene relación con el desarrollo, la estabilidad y las capacidades de las instituciones y autoridades de aplicación. La fórmula legal puede ser clara, adecuada y pertinente; sin embargo, las autoridades pudieran no tener las capacidades o los recursos necesarios para su aplicación.

Otra premisa de partida para la crítica a la decisión es reconocer que la norma andina nació en 1996, año desde el cual la política ambiental (que incluye los recursos genéticos) en los países andinos ha evolucionado de modo diferente, aunque se trate de lograr los mismos fines.

La Decisión Andina 391, como precepto, pudo haber sido una norma clara y concreta; no obstante, ya que su aplicación se encuentra en el terreno de la institucionalidad nacional de varios países diferentes entre sí, y con distintas capacidades y prioridades, existen varias debilidades que han caracterizado su aplicación, especialmente el inexistente control posacceso en todos los países de la región, debido a que desde la norma andina no existe referencia al tema.

Debe mencionarse también que definir indicadores de eficiencia para la aplicación de la norma andina puede llevar a injusticias no necesariamente evidentes, por ejemplo,

27 Perú. Ley 27811. Ley que establece el Régimen de Protección de los Conocimientos Colectivos de los Pueblos Indígenas vinculados a los Recursos Biológicos. Recuperado de https://www.indecopi.gob.pe/documents/20791/199826/ Ley27811-spanish.pdf/ebf10223-52ba-4a15-b790-90caf0a059a1 
considerar como un indicador de eficiencia el número de contratos de acceso firmados no revelaría si en estos contratos las condiciones de acceso han sido justas y equitativas, ni tampoco si la distribución de beneficios puede considerarse adecuada. Lo que puede afirmarse es que el régimen de acceso a los recursos genéticos no ha podido ser implementado de forma satisfactoria en la región andina.

Aunque la región andina haya sido la pionera en el tema de acceso a recursos genéticos, son pocas las historias de éxito en el tema y existen muy pocos ejemplos de accesos y contratos hechos en condiciones legales, y que todas las partes califiquen como justos y equitativos para todos. Peor aún, la reinversión en la conservación de la diversidad biológica desde un enfoque estratégico no ha sucedido; prueba de ello es la poca inversión de recursos fiscales en los sistemas de conservación de la diversidad biológica, recursos genéticos incluidos.

\section{Virtudes de la Decisión 391}

La norma andina en análisis es sin duda alguna un hito jurídico novedoso y sin precedentes en la legislación comparada; en ocasiones se olvida que fue promulgada en 1996, sin contar con más antecedente que el $\mathrm{CDB}$ que, en ese momento, solamente tenía cuatro años de vigencia.

Por eso ha sido régimen de inspiración para la legislación de otros países como Brasil, Costa Rica y Filipinas y, por tanto, constituye un patrimonio político de la región que debe capitalizarse y entenderse en su momento histórico.
Uno de los aspectos más destacables de la Decisión 391 es su rol como precedente en la historia de las negociaciones internacionales en materia de biodiversidad, lo cual permitió que se fortaleciera la capacidad de negociación internacional en materia de biodiversidad en el proceso de negociación del Protocolo de Nagoya (Ribadeneira Sarmiento, 2016).

Sería injusto no mencionar entre las virtudes de la Decisión Andina que al ser pionera en la reglamentación regional:

1. Promovió niveles de conciencia sobre los recursos genéticos y su importancia para los países de origen.

2. Ha ayudado a los países a reconocer el valor de los recursos genéticos y sus productos derivados y el conocimiento tradicional asociado, los cuales no habían tomado conciencia del valor estratégico de estos recursos y de la necesidad de proteger a los titulares del conocimiento tradicional.

3. Fundamentó la reivindicación de los derechos de los Estados sobre sus recursos de biodiversidad en general y genéticos en particular.

4. Ha servido para sensibilizar a los actores nacionales sobre los recursos genéticos y el valor general de la diversidad biológica.

5. Ha propiciado la generación de grupo de expertos, especialistas y estudiosos sobre acceso a recursos genéticos y sobre derechos de los titulares de los conocimientos tradicionales.

6. Ha incidido favorablemente en la capacitación de los delegados de los países andinos a los foros internacionales, ya 
sea dentro de grupos como Países Megadiversos ante el CDB o como Grupo Latinoamericano (GRULAC).

\section{Debilidades de la Decisión Andina 391}

\section{Limitaciones para el control}

Una muy seria deficiencia de la Decisión 391 es su limitación para el control durante el acceso a recursos genéticos y especialmente en el posacceso; como fácilmente puede verificarse en el texto de la norma andina, ninguno de sus preceptos se dedica al posacceso.

Este es un aspecto clave ya que existen dificultades para el control de movimientos y transferencias de recursos genéticos. Realmente no existe manera de controlar la salida y el intercambio de este tipo de recursos, pueden ser transportados en cualquier medio ya que están contenidos en recursos biológicos sometidos a ciertas restricciones como, por ejemplo, el permiso de exportación o la obligación de mantener un duplicado en una colección nacional.

Adicionalmente, existen abundantes recursos biológicos en colecciones ex situ que, como se ha reiterado, contienen unidades funcionales de herencia y, por tanto, de información genética, es decir, que se puede acceder a recursos genéticos sin necesidad de visitar el país de origen.

Para atender este tema es necesario definir estrategias de cooperación entre los centros de conservación ex situ y los países de origen, de modo que los segundos intervengan y estén informados cuando se acceda a sus recursos genéticos soberanos; ideal sería que los cen- tros de conservación ex situ se limiten al rol de custodios de dichos recursos.

\section{Limitación para la protección del conocimiento tradicional asociado a los recursos genéticos}

Como se deduce claramente del texto de la norma andina, la Decisión Andina 391 no es un instrumento diseńado expresamente para la protección del conocimiento tradicional asociado a los recursos genéticos, porque esta norma protege el conocimiento tradicional asociado al recurso genético, no al conocimiento per se ni al tradicional no asociado a recursos genéticos.

Las normas andinas relativa a la propiedad industrial (Decisión 486) (CAN, 2000) y al acceso a los recursos genéticos (Decisión 391) reconoce el derecho de los pueblos indígenas a que se salvaguarden y respeten sus conocimientos tradicionales y colectivos, y a decidir sobre ellos (CAN, s.f.); sin embargo, este reconocimiento es colateral al objeto principal de ambas decisiones.

Los pueblos indígenas tienen una instancia de participación en la CAN -el Consejo Consultivo de los Pueblos Indígenas-, que tiene competencia para pronunciar recomendaciones y declaraciones, pero cuyas decisiones no son vinculantes (CAN, 2007).

La plena protección efectiva de los derechos de las poblaciones indígenas, afrodescendientes y campesinas, entre estos aquellos asociados con el uso de los recursos, tenencia de la tierra, propiedad intelectual, identidad cultural o el mismo reconocimiento legal de las comunidades es aún una tarea pendiente. 
En relación con la protección de los conocimientos tradicionales de las poblaciones indígenas, afrodescendientes y campesinas se debe establecer un régimen andino especial de protección al conocimiento tradicional en cumplimiento de la Decisión Andina $391^{28}$. Esta norma andina es muy clara, debe elaborarse "una propuesta para establecer un régimen especial o una norma de armonización, según corresponda, que esté orientado a fortalecer la protección de los conocimientos, innovaciones y prácticas tradicionales de las comunidades indígenas, afroamericanas y locales" (CAN, 1996c), que esté en conformidad con esta Decisión y con normas como el Convenio 169 de la oIT (oIT, 1991) y el CDB. Dicha norma no se ha elaborado ni discutido en el seno de la CAN.

Mientras se logra este reto, urge diferenciar el conocimiento tradicional per se del conocimiento tradicional asociado a los recursos genéticos; una alternativa son los registros públicos que se usan en países como Perú e India.

Cuando se trata del acceso a los recursos genéticos, los derechos asociados a dichos recursos cobran especial importancia y deben ser considerados en las diversas etapas que involucra el mencionado acceso. Dependiendo del sistema legal del país, y de dónde se obtienen los recursos genéticos, los pueblos indígenas (en calidad de proveedores locales del recurso genético y de conocimiento tradicional asociado) pueden reclamar beneficios justos y equitativos de los beneficios que se deriven del acceso.

La distribución de beneficios sería un derecho adicional a los que ya tenían los pueblos indígenas, quienes en aplicación de las decisiones 391 y 486 pueden también:

1. Decidir sobre sus conocimientos, innovaciones y prácticas tradicionales asociadas a los recursos genéticos y productos derivados.

2. Intervenir y solicitar que se nieguen las solicitudes de patente de invención que no contaran con la autorización de uso de los conocimientos tradicionales, cuando los productos o procedimientos cuya protección se solicita han sido obtenidos o desarrollados a partir de los mencionados conocimientos.

3. Intervenir y solicitar que se anulen las patentes de invención concedidas en un país miembro de la CAN si se utilizan indebidamente conocimientos tradicionales de las comunidades indígenas, afrodescendientes o locales.

\footnotetext{
28 Decisión Andina 391. Disposición transitoria octava. La Junta elaborará, dentro de un plazo de tres meses posteriores a la presentación de estudios nacionales por los Países Miembros, una propuesta para establecer un régimen especial o una norma de armonización, según corresponda, que esté orientado a fortalecer la protección de los conocimientos, innovaciones y prácticas tradicionales de las comunidades indígenas, afroamericanas y locales, de conformidad con lo establecido en el artículo 7 de la presente Decisión, el Convenio 169 de la orT y el Convenio sobre la Diversidad Biológica.
}

A tal efecto, los Países Miembros deberán presentar los estudios nacionales respectivos, dentro del año siguiente a la fecha de entrada en vigencia de esta Decisión. 
Estos derechos no reemplazan la necesidad de contar con un régimen andino que proteja de modo directo a los conocimientos tradicionales de forma integral (CAN, 2005).

Es innegable que existe interés en acceder a recursos genéticos y al conocimiento tradicional asociado, ya sea con fines científicos o con fines comerciales, por ello es importante recuperar las lecciones aprendidas del debate internacional y los avances del trabajo internacional efectuado en pro del régimen sui generis de propiedad intelectual para el conocimiento tradicional que compete a la Organización Mundial de la Propiedad Intelectual (ompi).

\section{Limitaciones para enfrentar casos de accesos inapropiados o franca biopiratería}

Los accesos inapropiados, irregulares o de franca biopiratería constituyen una seria preocupación para los países de origen de los recursos genéticos. En trabajos anteriores se ha destacado la urgencia de un análisis legal de la biopiratería que permita establecer con claridad su definición, alcance y límites a la luz de los principios del derecho y no de la calificación política de corte reivindicativo que pudiera debilitar el concepto (Ribadeneira Sarmiento, 2008).

Las estrategias de defensa en el caso de accesos inapropiados o franca biopiratería no pueden basarse únicamente en la Decisión 391, ya que esta norma no tiene disposiciones aplicables a la investigación, reconocimiento y sanción de los casos que son accesos inapropiados, irregulares o franca biopiratería.

Los países comparten la preocupación por los casos de biopiratería de que han sido, son, o se sienten víctimas. Estos casos generalmente presentan algunos elementos comunes como los siguientes:

1. Uso privado directo o indirecto de recursos genéticos.

2. Aprovechamiento privado directo o indirecto del conocimiento tradicional asociado.

3. Generalmente son países con alta concentración de diversidad biológica, de los cuales se extrae el recurso genético a veces incluyendo el conocimiento tradicional asociado.

4. La irregularidad, injusticia y, en ciertos casos, la ilegalidad del acceso.

5. La falta de distribución de los beneficios resultantes del uso comercial y del no comercial.

6. La existencia de trámite de patentes o derechos de exclusividad.

En opinión de la autora, los elementos relacionados con el aprovechamiento privado directo o indirecto del recurso y del conocimiento asociado, y la falta de distribución de beneficios resultantes del uso comercial son elementos principales del acceso ilegítimo.

En tanto que la existencia o el trámite de patentes o derechos de exclusividad sería accidental y, curiosamente, es este elemento accidental uno de los más controversiales (Ribadeneira Sarmiento, 2014).

En la región andina, la prevención y lucha contra la biopiratería ha generado importantes ejemplos a nivel de legislación e institucionalización, y algunos casos han sido sistematizados. Sin embargo, las lecciones aprendidas 
aún no han sido asimiladas por los países de origen que han vivido el acceso ilegítimo o ilegal sufrido por sus vecinos.

En el tema de la prevención y lucha contra la biopiratería, de los países andinos el más avanzado es Perú. Como se mencionó, este país cuenta con un instrumento legal, la Ley de Protección al Acceso a la Diversidad Biológica Peruana y los Conocimientos Colectivos de los Pueblos Indígenas ${ }^{29}$, que incluye una definición legal de biopiratería ${ }^{30}$, y ha institucionalizado la gestión pública a través de la Comisión Nacional de Prevención de la Biopiratería en el Perú ${ }^{31}$.

Es deseable que la experiencia peruana se extienda por la región, y que se arribe a una fórmula regional que posibilite acciones legales de prevención y seguimiento (Ribadeneira Sarmiento, 2014).

\section{El carácter proteccionista impide el reconocimiento del valor de los recursos genéticos}

Aunque la Decisión 391 fue el primer instrumento regional pos-Conferencia de Río
1992 que se promulgó para normar el acceso a los recursos genéticos, no necesariamente ha facilitado el reconocimiento de los múltiples valores de dichos recursos: estratégico, monetario (económico, transferencia de tecnología, capacitación, etc.) y no monetario (existencia, conservación de la diversidad biológica, etc.).

La crítica en este aspecto es que la norma plantea un carácter proteccionista y adopta posiciones "en contra de la bioprospección extranjera" sin reconocer que el acceso a los recursos genéticos podría implicar una posición privilegiada para la negociación de beneficios como la transferencia de tecnología y la creación de otras capacidades locales. Así mismo, olvida que existen investigadores e innovadores nacionales interesados en acceder a los recursos genéticos para desarrollar o mejorar productos.

El carácter reivindicativo que tiene la norma andina no es necesariamente la mejor aproximación para los procesos de negociación del acceso a recursos genéticos, ya que no permite una posición estratégica. Tal pareciera que la norma andina se hubiera escrito

29 Perú. Ley 28.216. Ley de Protección al Acceso a la Diversidad Biológica Peruana y los Conocimientos Colectivos de los Pueblos Indígenas, 30 de abril del 2004.

30 Perú. Ley 28.216. Disposiciones complementarias y finales. Tercera. Para los efectos de la aplicación de la presente ley se entiende por biopiratería, el acceso y uso no autorizado y no compensado de recursos biológicos o conocimientos tradicionales de los pueblos indígenas por parte de terceros, sin la autorización correspondiente y en contravención de los principios establecidos en el CDB y las normas vigentes sobre la materia. Esta apropiación puede darse a través del control físico, mediante derechos de propiedad sobre productos que incorporan estos elementos obtenidos ilegalmente o en algunos casos mediante la invocación de los mismos.

31 Perú. La Ley 28216. Creó la Comisión Nacional para la Protección al Acceso a la Diversidad Biológica Peruana y los Conocimientos Colectivos de los Pueblos Indígenas, 7 de abril de 2004. 
para "defender a los países andinos" de los potenciales accesos a sus recursos genéticos y no para "facilitar y promover accesos mutuamente beneficiosos".

La posición defensiva de la Decisión 391 no contempla que los interesados en el acceso no necesariamente son "otros y extranjeros", sino que pueden ser investigadores y estudiosos "nacionales" a quienes es importante estimular y apoyar en lugar de sospechar de sus intenciones y limitar sus investigaciones.

\section{Multiplicidad de contratos accesorios}

Además de las normas de la Decisión 391, para la elaboración del contrato deben considerarse las resoluciones 414 y 415: Adopción del Modelo Referencial de Contrato de Acceso a Recursos Genéticos, promulgadas el mismo año en que se promulgó la Decisión ${ }^{32}$. Ambas resoluciones contienen los modelos referenciales, en el primer caso de la solicitud de acceso y en el segundo del modelo de contrato.

Un gran inconveniente relativo al contrato de acceso el hecho de que no se trate de un solo contrato (art. 41 D391) sino de varios:

1. Contrato de acceso principal (art. 32 D391); y,

2. Contratos accesorios (art. 41 D391) entre el Estado y:
- Propietario del predio en que se encuentra el recurso genético.

- Centro de conservación ex situ.

- Propietario del recurso biológico que contenga el recurso genético.

- Contrato con institución nacional de apoyo.

- Contrato de administración (Disposición 5ta. D391).

- Contrato de intermediación (Disposición 5ta. D391).

- Contrato de depósito (Disposición 5ta. D391).

- Contrato de acceso marco (Art. 36 D391).

- Contrato por uso de conocimiento tradicional asociado (art. 35 D391) anexo al contrato principal.

Aunque no es necesario suscribir todos los contratos en todos los casos de acceso a recursos genéticos, es innegable que la existencia de esta multiplicidad de contratos contribuye a generar desconfianza de los interesados que teman se requiera más tiempo y requisitos para celebrar los contratos necesarios a su caso particular.

La multiplicidad de contratos contribuye con la demora de los procesos administrativos requeridos para el acceso.

32 Resolución 414 de la Junta del Acuerdo de Cartagena - Adopción del modelo referencial de solicitud de acceso a recursos genéticos - Anexo Solicitud de acceso. Y Resolución 415 de la Junta del Acuerdo de Cartagena - Adopción del modelo referencial de solicitud de acceso a recursos genéticos - Anexo Contrato de Acceso (modelo referencial). Ambas publicadas en la Gaceta Oficial 217 del Acuerdo de Cartagena, año XIII, 5 de agosto del 1996. 


\section{Desincentivo a la investigación científica nacional}

La existencia de demasiados tipos de contratos conspira contra la eficiencia de la Decisión 391. No solo son pocos los contratos firmados, sino que tampoco se cuenta con seguimiento oficial sistematizado y aún menos con un análisis objetivo de los beneficios resultantes.

Lo más problemático de los requisitos de la norma andina es el poco incentivo que esto representa para la investigación nacional de los países andinos, empezando porque las autoridades nacionales generalmente no diferencian las solicitudes con fines de investigación, de las que tienen fines comerciales. De hecho solo Ecuador, a través de la norma que regula el procedimiento para la suscripción de Contratos Marco de Acceso a Recursos Genéticos ${ }^{33}$, tiene un instrumento específico para favorecer la investigación científica que requiere acceso a recursos genéticos; sin embargo, aunque el reglamento y procedimiento nacional sí diferencien las solicitudes de interés comercial del interés científico, las tramitan en la misma ventanilla única.

La investigación científica es un beneficio no monetario que generalmente no es evidente. El primer beneficio de la investiga- ción es el incremento y la depuración de la información científica disponible, que apoya las labores aplicadas de conservación y uso sostenible de biodiversidad al posibilitar un mejor conocimiento de la biodiversidad. El segundo beneficio es la formación de nuevos investigadores, profesionales y talentos en el manejo y conservación de biodiversidad (Bendix, et al., 2010).

\section{DECISIÓN ANDINA 391: COYUNTURA Y FUTURO}

En el pasado se ha intentado reformar el régimen de acceso a recursos genéticos en la región andina en varias ocasiones; la última data de 2013, a propósito de la vi Reunión del Comité Andino de Recursos Genéticos, realizada en Lima en abril de $2013^{34}$. Este comité tenía como tarea elaborar propuestas con el fin de modificar el texto de la Decisión 391 y actualizar su texto a la luz del Protocolo de Nagoya.

Durante 2013, el Comité estaba trabajando en la primera fase del proceso de revisión, que consistía en recoger con las opiniones técnicas de las autoridades nacionales, cuando pocos meses se adoptó la Decisión Andina 792 sobre la Implementación de la reingeniería del sistema andino de integración (CAN, 2013) ${ }^{35}$,

33 Ecuador. Norma que regula el procedimiento para la suscripción de Contratos Marco de Acceso a Recursos Genéticos, promulgada por el Acuerdo Ministerial 034, publicado en el Registro Oficial 449, 2 marzo del 2015.

34 En el Comité Andino de Recursos Genéticos, como en todos los comités andinos, participan de pleno derecho y con las mismas facultades, las autoridades nacionales delegadas por todos los países andinos.

35 El artículo 3 de esta decisión dispone "Quedan suprimidos los Comités y Grupos Ad Hoc que no estén relacionados de forma directa con los lineamientos y ámbitos de acción priorizados” (CAN, 2013). 
que eliminaba todos los comités especializados, incluido obviamente el Comité Andino de Recursos Genéticos.

$\mathrm{Al}$ año siguiente, la Decisión 797 (CAN, $2014)^{36}$ emitió una lista de comités especializados que se reactivaban; el Comité Andino de Recursos Genéticos no consta en este listado.

Tradicionalmente, en materia de acceso a recursos genéticos y conocimientos tradicionales asociados, la Secretaría General de la Comunidad Andina era el órgano andino más activo en la materia. A la Secretaría le correspondía, entre sus funciones, ejercer la secretaría del Comité Andino de Recursos Genéticos; y, además, el texto de la Decisión 391 le daba varias tareas:
1. Constituir mecanismos de notificación entre los países miembros respecto de las solicitudes, resoluciones y autorizaciones $\left(\right.$ art. 48) ${ }^{37}$.

2. Constituir mecanismos de comunicación entre los países para notificar las normas legales nacionales relacionadas con la Decisión (art. 49) ${ }^{38}$.

3. Recibir recomendaciones del Comité Andino sobre Recursos Genéticos acerca de modelos de documentación común, en particular, la que permita comprobar fácilmente la codificación e identificación de los recursos genéticos y sus productos derivados, así como la legalidad del acceso (art. 51 lit. e) ${ }^{39}$.

36 Decisión Andina 797: Comités y grupos ad hoc de la Comunidad Andina en el marco de la reingeniería del Sistema Andino de Integración, aprobada en la Trigésimo Octava Reunión del Consejo Andino de Ministros de Relaciones Exteriores en reunión ampliada con los representantes titulares ante la Comisión de la Comunidad Andina (14 de octubre de 2014). Lima, Perú. Esta decisión incluye un listado de 27 comités que son los únicos que se consideran relacionados con los lineamientos y ámbitos de acción priorizados en la Decisión 792; no consta el Comité Andino de Recursos Genéticos.

37 Decisión Andina 391: Titulo Ix. De las Notificaciones entre los Países Miembros. Artículo 48. Los Países Miembros se notificarán de manera inmediata, a través de la Junta, todas las solicitudes, resoluciones y autorizaciones de acceso, así como la suspensión y terminación de los contratos que suscriban. Asimismo, se notificarán entre sí la celebración de cualquier acuerdo bilateral o multilateral sobre la materia, los cuales deberán ser conformes con lo dispuesto en la presente Decisión.

38 Decisión Andina 391: Artículo 49. Sin perjuicio de lo dispuesto en el artículo anterior, los Países Miembros, entre sí y a través de la Junta, se comunicarán de manera inmediata, las disposiciones, decisiones, reglamentos, sentencias, resoluciones y demás normas y actos adoptados a nivel interno, que tengan relación con lo dispuesto en la presente Decisión.

39 Decisión Andina 391: Título XI. Del Comité Andino sobre Recursos Geneticos. Artículo 51. Créase el Comité Andino sobre Recursos Genéticos, el cual estará conformado por los Directores de las Autoridades Nacionales Competentes en materia de Acceso a Recursos Genéticos o sus representantes, por los asesores y por los representantes de otros sectores interesados, que designe cada País Miembro. El Comité estará encargado de:

e) Recomendar a la Junta para su adopción mediante Resolución, modelos de documentación comunes, en particular, aquellos que permitan comprobar con facilidad la codificación e identificación de los recursos genéticos y sus productos derivados, así como la legalidad del acceso. 
4. Perfeccionar o ajustar el procedimiento de acceso a recursos genéticos (Disposición Final Tercera) ${ }^{40}$.

5. Recibir la designación y acreditación de la autoridad nacional de acceso a recursos genéticos y acreditarla ante la Junta (Disposiciones Transitorias Quinta) ${ }^{41}$.

6. Recibir las acreditaciones de los representantes de los países al Comité Andino sobre Recursos Genéticos (Disposición Transitoria Sexta) ${ }^{42}$.

7. Coordinar con los países miembros la ejecución de los estudios relativos al movimiento transfronterizo de los organismos vivos modificados que fundamenten la adopción de un régimen común sobre bioseguridad, en el marco del CDB (Disposición Transitoria Séptima) ${ }^{43}$.

8. elaborar una propuesta de régimen especial o norma de armonización, según corresponda, para fortalecer la protección de los conocimientos de las comunidades indígenas, afroamericanas y locales (Disposición Transitoria Octava) ${ }^{44}$.

Ante la eliminación del Comité, sus gestiones se han visto comprometidas $y$, en función del proceso de reestructuración de la CAN, la reforma y actualización de la Decisión Andina 391 (a la fecha de elaborar este artícu$1 \mathrm{l}^{45}$ ) se ha detenido, y actualmente no existe claridad sobre cómo ni cuándo continuará.

40 Decisión Andina 391: Disposiciones finales. Tercera. La Junta, mediante resolución y previa opinión del Comité Andino sobre Recursos Genéticos, podrá perfeccionar o ajustar el procedimiento previsto en los Capítulos I y II del Título V de la presente Decisión.

41 Disposiciones transitorias. Quinta. En un plazo no mayor de 30 días hábiles contados a partir de la fecha de entrada en vigencia de esta Decisión, los Países Miembros designarán la Autoridad Nacional Competente en materia de acceso a recursos genéticos y la acreditarán ante la Junta.

42 Disposiciones transitorias. Sexta. Los Países Miembros, en un plazo no mayor de 30 días hábiles contados a partir de la fecha de entrada en vigencia de esta Decisión, acreditarán ante la Junta del Acuerdo de Cartagena sus representantes ante el Comité Andino sobre Recursos Genéticos.

43 Disposiciones Transitorias. Séptima. Los Países Miembros adoptarán un régimen común sobre bioseguridad, en el marco del Convenio sobre la Diversidad. Para tal efecto, los Países Miembros en coordinación con la Junta, iniciarán los estudios respectivos, particularmente en lo relacionado con el movimiento transfronterizo de los organismos vivos modificados producto de la biotecnología.

44 Disposiciones Transitorias. Octava. La Junta elaborará, dentro de un plazo de tres meses posteriores a la presentación de estudios nacionales por los Países Miembros, una propuesta para establecer un régimen especial o una norma de armonización, según corresponda, que esté orientada a fortalecer la protección de los conocimientos, innovaciones y prácticas tradicionales de las comunidades indígenas, afroamericanas y locales, de conformidad con lo establecido en el artículo 7 de la presente Decisión, el Convenio 169 de la ort y el Convenio sobre la Diversidad Biológica. A tal efecto, los Países Miembros deberán presentar los estudios nacionales respectivos, dentro del año siguiente a la fecha de entrada en vigencia de esta Decisión.

45 Septiembre de 2016. 
Debido a lo anterior, en febrero 2016, el Parlamento Andino ${ }^{46}$ inició el análisis técnico y académico para diseñar y revisar un borrador de Marco Normativo Andino de Medidas de Salvaguarda de los Recursos Genéticos y los Conocimientos Tradicionales Asociados. Recientemente, en la sesión del Parlamento Andino del 24 de febrero de 2017 este marco normativo fue aprobado; lamentablemente, debido a la extensión de este artículo, el análisis de este documento será efectuado en un artículo específico y posterior.

\section{CONCLUSIONES}

El acceso a recursos genéticos ha sido un tema controversial que ha causado conflictos a nivel local, nacional e internacional. Por ello es tan destacable que tras la suscripción del Convenio de Diversidad Biológica, el primer instrumento legal sobre en la materia haya sido la Decisión Andina 391 de 1996. Sin embargo, y sin perjuicio de reconocer que la norma andina de acceso a recursos genéticos fue un suceso que sirvió de referencia mundial, es necesario reconocer que tras veinte ańos la norma precisa actualización por varias razones.

De un lado, la evolución de la ciencia y la tecnología hacen ya inaplicable la Decisión 391. De otro, la norma andina debe guardar armonía con el Protocolo de Nagoya que al momento se encuentra ratificado por Bolivia y Perú, y en análisis para su ratificación en Ecuador y Colombia.

La reglamentación de la Decisión 391 en los países andinos tuvo suerte dispar: en un país se reglamentó muy pronto (Bolivia); en otros, tras largos procesos nacionales (Ecuador y Perú), y en un cuarto país no se reglamentó propiamente sino que han sido otros instrumentos legales los que han clarificado las condiciones de aplicación (Colombia).

Aunque la región andina haya sido la pionera en el tema, son pocas las historias de éxito al respecto, y existen muy pocos ejemplos de accesos y contratos hechos en condiciones legales y que las partes califiquen como justos y equitativos para todos.

Cuando se promulgó la Decisión Andina 391 en 1996 se generaron muchas expectativas tanto para los usuarios (investigadores, empresas dedicadas al desarrollo tecnológico, entre otros) como para los proveedores de los recursos genéticos; no obstante, en la práctica no se han logrado los resultados esperados debido a:

1. Las limitaciones para acceder al recurso.

2. Las demoras en los procedimientos.

3. La poca claridad para la negociación de los contratos de acceso.

4. La falta de lineamientos que orienten la distribución de los beneficios resultantes del acceso.

46 El Parlamento Andino es el órgano parlamentario del sistema andino y tiene jurisdicción en Bolivia, Chile, Colombia, Ecuador y Perú. Al Parlamento le corresponde, entre otras competencias: i) la promoción del proceso de integración, ii) la armonización de las legislaciones de los países miembros y iii) la generación normativa del proceso de integración, a través de iniciativas normativas comunitarias. 
5. Las dificultades prácticas en el caso de los recursos genéticos transfronterizos, así como en materia de la protección de los conocimientos tradicionales asociados al recurso.

Es innegable que la vigencia de la Decisión 391 durante estos veinte años ha generado varias y valiosas lecciones. Se ha aprendido por ejemplo:

1. Que es necesario mantener una posición más estratégica que defensiva para negociar.

2. Que se debe distinguir la investigación científica de la investigación con fines comerciales, para poder fomentar la primera.

3. Que es necesario hacer monitoreo también en el posacceso, entre otras cosas para poder verificar los beneficios que se distribuirán.

4. Que es necesario fortalecer a las autoridades nacionales competentes en la materia.

5. Que se deben apoyar los esfuerzos nacionales en el control de la biopiratería.

6. Que es necesario recuperar la instancia regional de coordinación en acceso a recursos genéticos que fue eliminada cuando se suprimió el Comité Andino, entre otras.

Ideal sería que estas y otras lecciones aprendidas durante la vigencia de la Decisión 391 fueran capitalizadas en un instrumento legal que, reconociendo los derechos soberanos de los países de origen, facilite el acceso y permita efectuar monitoreo y control posacceso.
Finalmente, es deseable que el reciente Marco Normativo Andino de Medidas de Salvaguarda de los Recursos Genéticos y los Conocimientos Tradicionales Asociados contribuya a mantener recuperar regionalmente una posición más estratégica y crítica sobre el acceso a los recursos genéticos, que apoye los procesos de ajustes que un sistema regional requiere, y que permita avanzar con los temas y las tareas pendientes.

Queda aún por trabajar en los otros enlaces que permitirían enfrentar las tareas pendientes en la materia, por ejemplo, proteger los derechos de los titulares del conocimiento tradicional asociado a los recursos genéticos y avanzar desde la perspectiva de la reivindicación de los derechos del Estado sobre los recursos genéticos a posiciones más estratégicas y propositivas.

\section{REFERENCIAS}

Bendix, J., Paladines, B., Ribadeneira Sarmiento, M., Romero, L. M., Valarezo, C. y Beck, E. (2010). Benefit sharing by research, education and knowledge transfer - A success story of biodiversity research in southern Ecuador. En Brooks, L. A. y Aricò, S. (eds.). Tracking Key Trends in Biodiversity Science and Policy. Paris: Unesco.

Bolivia. Reglamento de la Decisión 391 Régimen de Acceso a los Recursos Genéticos, promulgado el 21 de junio de 1997. Recuperado de http://www. lexivox.org/norms/BO-RE-Ds24676A.xhtml.

Cabrera A., Ribadeneira M. y Camacho D. (2014). La propiedad intelectual en verde: obtenciones vegetales, indicaciones geográficas y cambio climático. Guía para el capacitador, manual para el alumno 
y presentación. Quito: Instituto Ecuatoriano de la Propiedad Intelectual, IEPI (sin publicar).

Carrión Eguiguren, E. (1987). Curso de derecho civil: de los bienes. Ecuador: Ediciones de la Pontificia Universidad Católica del Ecuador.

Comunidad Andina (CAN) (2005). Elementos para la protección sui generis de los conocimientos tradicionales colectivos integrales desde la perspectiva indigena. Unidad de Publicaciones de la CAF. Recuperado de http://www.comunidadandina. org/Upload/201164175851libro_perspectiva_indigena.pdf

Comunidad Andina (Can) (s. f.). Derechos de los pueblos indigenas en la Comunidad Andina. Recuperado de http://www.comunidadandina.org/Upload/ 2013819121949indigenasJuL2013.pdf

Comunidad Andina (CAN) (1993). Decisión 345 sobre régimen común de protección a los derechos de los obtentores de variedades vegetales. Recuperado de http://www.wipo.int/edocs/lexdocs/laws/ es/pe/pe005es.pdf

Comunidad Andina (CAN) (1996a). Tratado de creación del Tribunal de Justicia de la Comunidad Andina. Recuperado de https://idatd.cepal.org/ Normativas/Can/Espanol/Tratado_de_Creacion_del_Tribunal_de_Justicia.pdf

Comunidad Andina (CAN) (1996b). Protocolo modificatorio del tratado de creación del Tribunal de Justicia de la Comunidad Andina (Protocolo de Cochabamba). Recuperado de http://www. sice.oas.org/trade/junac/decisiones/DEC472s.ASP

Comunidad Andina (CAN) (1996c). Decisión Andina 391: Régimen común sobre acceso a los recursos genéticos de la Comunidad Andina de Naciones. Recuperado de http://www.wipo.int/edocs/ lexdocs/laws/es/can/can011es.pdf

Comunidad Andina (CAN) (1996d). Resolución 414 la Junta del Acuerdo de Cartagena - Adopción del modelo referencial de solicitud de acceso a recursos genéticos - Anexo solicitud de acceso. Gaceta Oficial del Acuerdo de Cartagena, XIII (217).

Comunidad Andina (CAN) (1996e). Resolución 415 de la Junta del Acuerdo de Cartagena - Adopción del modelo referencial de solicitud de acceso a recursos genéticos - Anexo Contrato de acceso (modelo referencial). Gaceta Oficial del Acuerdo de Cartagena, XIII (217).

Comunidad Andina (CAN) (2000a). Decisión Andina 344 sobre el régimen común sobre propiedad industrial. Recuperado de http://www.wipo.int/ edocs/lexdocs/laws/es/can/can012es.pdf

Comunidad Andina (CAN) (2007). Decisión Andina 674 sobre el establecimiento del Consejo Consultivo de los Pueblos Indígenas. Recuperado de http://andina.vlex.com/vid/consejo-consultivopueblos-indigenas-32939719

Comunidad Andina (CAN) (2013). Decisión Andina 792 sobre la implementación de la reingeniería del Sistema Andino de Integración. Recuperado de http://www19.iadb.org/intal/intalcdi/ PE/2013/12682.pdf

Comunidad Andina (CAN) (2014). Decisión Andina 797 sobre comités y grupos ad hoc de la Comunidad Andina en el marco de la reingeniería del Sistema Andino de Integración, aprobada en la Trigésimo Octava Reunión del Consejo Andino de Ministros de Relaciones Exteriores en reunión ampliada con los representantes titulares ante la Comisión de la Comunidad Andina. Recuperado de http://andina.vlex.com/vid/-539178382

Conferencia de las partes (2014). Protocolo de Nagoya sobre el acceso a los recursos genéticos y participación justa y equitativa en los beneficios que se deriven de su utilización al Convenio de Diversidad Biológica. Japón: onU. Recuperado 
de https://www.cbd.int/abs/nagoya-protocol/ signatories/default.shtml.

Estrella, J., Manosalvas, R., Mariaca, J. y Ribadeneira Sarmiento, M. (2005). Biodiversidad y recursos genéticos: una guía para su uso y acceso en el Ecuador. Quito: Ecociencia, INIAP, MAE y ABYA YALA. FAO (2004). Tratado internacional sobre recursos fitogenéticos. Ginebra: onU.

Glowka, L. et al. (1996). Guía del Convenio sobre la Diversidad Biológica. Gland y Cambridge: UICN.

Gobierno de Ecuador (2015). Norma que regula el procedimiento para la suscripción de Contratos Marco de Acceso a Recursos Genéticos, promulgado por el Acuerdo Ministerial 034. Registro Oficial 449.

Gobierno de Ecuador (s. f.). Decreto Supremo 003-2009-Minam ratificación de la aprobación del Reglamento de Acceso a los Recursos Genéticos.

Ley 27811, que establece el Régimen de Protección de los Conocimientos Colectivos de los Pueblos Indígenas vinculados a los Recursos Biológicos. Recuperado de https://www.indecopi.gob.pe/ documents/20791/199826/Ley27811-spanish. pdf/ebf10223-52ba-4a15-b790-90caf0a059a1

Ley 28216. Ley de Protección al Acceso a la Diversidad Biológica Peruana y los Conocimientos Colectivos de los Pueblos Indígenas. Recuperado de http://www.wipo.int/wipolex/en/text. jsp?file_id=179602

Ministerio de Comercio Exterior. Decreto 730 de 1997, por el cual se determina la Autoridad Nacional Competente en materia de acceso a los recursos genéticos. Recuperado de https://www.cbd.int/ doc/measures/abs/msr-abs-co3-es.pdf

Ministerio de Desarrollo Sostenible, Viceministerio de Recursos Naturales y Medio Ambiente, Dirección General de Biodiversidad (2004).
La experiencia boliviana en la aplicación de la Decisión 391: Régimen común sobre acceso a recursos genéticos. La Paz: Ministerio de Desarrollo Sostenible.

Ministerio del Ambiente y Desarrollo Sostenible. Resolución 1348 de 2014, por la cual se establecen las actividades que configuran acceso a los recursos genéticos y sus productos derivados para la aplicación de la Decisión Andina 391 de 1996 en Colombia y se toman otras determinaciones. Recuperado de http://www.icbf.gov.co/ cargues/avance/docs/resolucion_minambienteds_1348_2014.htm

Ministerio del Medio Ambiente. Resolución 620 de 1997, por la cual se delegan algunas funciones contenidas en la Decisión 391 de la Comisión del Acuerdo de Cartagena y se establece el procedimiento interno para tramitar las solicitudes de acceso a los recursos genéticos y sus productos derivados. Recuperado de http://www. minambiente.gov.co/images/BosquesBiodiversidadyServiciosEcosistemicos/pdf/Recursos _ Gen\%C3\%A9ticos_/resoluci\%C3\%B3n_620_ de_1997.pdf

Naciones Unidas (1992). Convenio de Diversidad Biológica. Ginebra: onu.

Organización Internacional del Trabajo (огт) (1991). Convenio 169 sobre Pueblos Indígenas y Tribales en Países Independientes. Recuperado de http:// www.ilo.org/dyn/normlex/es/f?p=NORMLEXPUB :12100:0::NO::P12100_ILO_CODE:CI69

Reglamento Nacional al Régimen Común Sobre Acceso a los Recursos Genéticos en Aplicación a la Decisión 391 de la Comunidad Andina, promulgado por vía del Decreto Ejecutivo 905. Registro Oficial 553.

Ribadeneira Sarmiento, M. (2008). La biopiratería, el desafío de construir un camino entre la acusación 
política y la categoría legal. En Conservación de la biodiversidady politica ambiental (6ta. Convocatoria). Buenos Aires: Talleres Gráficos.

Ribadeneira Sarmiento, M. (2014). El Protocolo de Nagoya sobre Acceso a los recursos genéticos y participación justa y equitativa en los beneficios que se deriven de su utilización: cuatro retos para su implementación nacional en países de América Latina y el Caribe. Revista Opera 15. Recuperado de http://revistas.uexternado.edu. co/index.php?journal=opera\&page =article\&op =view\&path $\% 5 B \% 5 \mathrm{D}=3967$

Ribadeneira Sarmiento, M. (2016). El régimen andino de acceso a los recursos genéticos, una reforma necesaria [Documento de trabajo en revisión].

Ribadeneira Sarmiento, M. (2016). Recursos genéticos y conocimientos tradicionales en el Convenio sobre la Diversidad Biológica y el Protocolo de
Nagoya, algunas dificultades jurídicas y operativas. En Roca, S. (ed.). Biodiversidad y propiedad intelectual en disputa: situación, propuestas y politicas públicas. Lima: Universidad ESAN.

Rosell, M. (1999). Marco institucional y seguridad juridica en la Comunidad Andina de Naciones. Lima: Documentos y publicaciones.

Secretaría del Convenio de Diversidad Biológica (s.f.). Protocolo de Nagoya. Recuperado de https:// www.cbd.int/abs/nagoya-protocol/signatories/ default.shtml

Tapia, C., Falconí, E., Martínez, M., Buitrón, X. y Ribadeneira Sarmiento, M. (2012). El Sistema Multilateral del Tratado Internacional sobre recursos fitogenéticos para la alimentación y la agricultura. Análisis e implicaciones de su implementación en el Ecuador. Quito: INIAP. 